\title{
Research of Pelagic Fishing Operating Personnel Optimization Technology Based on Post Competence
}

\author{
Jiaoyun Shao \\ College of Engineering Science and Technology \\ Shanghai Ocean University \\ Shanghai, China \\ E-mail: yjys1107@163.com
}

Shouqi Cao*

College of Engineering Science and Technology

Shanghai Ocean University

Shanghai, China

E-mail: sqcao@shou.edu.com

* Corresponding Author

\author{
Chengming Chen \\ College of Engineering Science and Technology \\ Shanghai Ocean University \\ Shanghai, China \\ E-mail: cmchen@shou.edu.com \\ Ying Chen \\ College of Engineering Science and Technology \\ Shanghai Ocean University \\ Shanghai, China \\ E-mail: cy07120810@163.com
}

\begin{abstract}
It is easy to cause a series of problems such as low work efficiency and production by personal experience judgment to allocate pelagic fishing operating people. To improve the overall efficiency of fishing line, this paper introduces the concept of post competence, and makes methods to improve personnel's working efficiency on the fishing and processing production line. On the basis of illustrating pelagic fishing operation process, this paper analyses the nature of the fishing production operation. Characteristics and calculation method of the fishing operating post competence are established. Entropy value method is used to calculate index weight coefficient, which determines the calculation formula of post competency. Based on the post adaptability, fishery economy benefit and production efficiency optimization, the most optimized personnel post competence matrix model is developed. A heuristic algorithm is designed to solve the model. Finally, based on the instance of trawler fishing and production process, this paper analyses an example of research content, and the result shows the approach is feasible.
\end{abstract}

Keywords- Pelagic Fishing; Fishing Boats Working; Personnel Allocation; Post Competence; Heuristic Algorithm

\section{INTRODUCTION}

At present, in the process of production operation on the pelagic fishing ship, the personnel allocation of pelagic fishing and machining process is still no in-depth study. Now the workers management still depends on a few managers' experience and managers' personal judgment. To a certain extent, this leads to the unreasonable personnel allocation, low working efficiency and economic loss. Especially like Seine, trawl practices can achieve a few tons or even dozens of tons of fish at one time. It needs to balance the production line to improve the processing efficiency when the number of people on board is fixed, and the fish number is larger.
As a measure of personnel work quality and the efficiency factor, post competency degree is researched and used in many fields [1-2]. Improvement in the sum of production line workers' post competence has helped improve the working efficiency. This paper uses the optimization goal of maximu m post competency degree to optimize the allocation of production line. The optimal allocation of personnel post competency degree maximu $\mathrm{m}$ model is established. A heuristic algorithm is designed to solve the model. Finally, it analyses an example of research content, and proves the approach is feasible.

\section{PELAGIC FISHINGPOST COMPETENCY DEGREE INDEX}

Degree of post competency refers to the personal characteristics of excellent performance of workers in specific jobs, enterprise environment and culture. It also can be explained as the ability of taking this post [3]. Before establishing post competency degree optimization model, the fishing post competency degree index should be determined firstly, a system of post competency degree should be established, and finally the competence factors and the factors weight distribution should be determine.

\section{A. Post competency distribution}

The establishment of the index system of post competency degree should refer to practical problems [4]. On the production line of pelagic fishing ship, because of the particularity of the work environment and job requirements, the higher the workers' professional skill is, the higher ability the task will be performed. The longer the people working in a job, the higher the ability to perform this task is. The higher the operating performance, the higher the ability to perform this task is. Therefore, this paper uses the working skills, working time and job performance as the personnel competence factors. The letters are defined as follows: 
$p_{m}$ - Fishing operation personnel $\quad(m=1,2,3, \ldots, i)$;

$s_{n} \quad$ - Fishing and processing work post $(n=1,2,3, \ldots, j)$;

$\alpha_{m n}$ - Competent factor for computing skills in the fishing line operation;

$K_{m n}$ - Skill level of $p_{m}$ on the ${ }^{s_{n}}$ post;

$\beta_{m n}$ - Competent factor for cumulative time in the fishing line operation;

$T_{m n}$ - Cumulative working hours of $p_{m}$ working on $s_{n}$ in a calculation cycle;

$\gamma_{m n}$ - Competent factor for operating performance in the fishing line operation;

$R_{m n}$ - Operating performance of $p_{m}$ working on $S_{n}$ in a calculation cycle;

$$
\begin{aligned}
& \alpha_{m n}=K_{m n} / \max _{1 \leq m \leq i}\left\{K_{m n}\right\} \\
& \beta_{m n}=T_{m n} / \max _{1 \leq m \leq i}\left\{T_{m n}\right\} \\
& \gamma_{m n}=R_{m n} / \max _{1 \leq m \leq i}\left\{R_{m n}\right\}
\end{aligned}
$$

\section{B. The determination of index weight coefficients}

This paper uses the entropy value method to establish a post competency index weight, and then uses weighted way to sum factors. Finally it is concluded fishing personnel competence level of the corresponding post. Define the meaning of the letter as follows:

$d_{m x}$ - Statistical data of the $x$ indicators for worker whose number is $m(m=1,2,3, \ldots, i ; x=\alpha, \beta, \gamma)$

$\rho_{\alpha}$ - Weight coefficient of work skill factor;

$\rho_{\beta}$ - Weight coefficient of work time factor;

$\rho_{\gamma}$ - Weight coefficient of work performance factor;

$w_{m n}$ - Competency index of $p_{m}$ on $s_{n}$ post;

The weight is calculated by using entropy method.

Then normalize $d_{m x}$, it is concluded that:

$$
c_{m x}=d_{m x} / \sum_{m=1}^{i} d_{m x}
$$

Calculate the $x$ entropy of indicators, it is concluded that:

$$
g_{x}=-\sum_{m=1}^{i} c_{m x} \ln c_{m x}
$$

The smaller entropy of indicator is, the more the difference coefficient will be, and the greater the weight will be. Calculate the index difference coefficient as follows:

$$
e_{x}=-g_{x}+1
$$

Normalize $e_{x}$, and acquire the expression of weight coefficient:

$$
l_{x}=e_{x} / \sum_{l=1}^{3} h_{x}
$$

Then competency index of $p_{m}$ on $s_{n}$ post is

$$
w_{m n}=\rho_{\alpha} \alpha_{m n}+\rho_{\beta} \beta_{m n}+\rho_{\gamma} \gamma_{m n}
$$

\section{PERSONNEL OPTIMIZATION}

After establishing personnel post competency degree matrix by using working skills, working hours and working performance as post competency degree indexes, in order to ensure production balance and the most reasonable allocation between each station on fishing and production line, it is need to build a model by using the biggest staff competence as the target. It is concluded personnelallocation when competencies are the largest.

Fishing processing operation personnel allocation optimization model is established as follows:

$h_{m n}$ - The staff $m$ assigned to positions of $n$;

$R$ - Maximum post competency degree.

The objective function:

$$
\begin{aligned}
& R=\max \sum_{m=1}^{i} \sum_{n=1}^{j} w_{m n} h_{m n} \\
& =\max \sum_{m=1}^{i} \sum_{n=1}^{j} h_{m n}\left(\rho_{\alpha} \alpha_{m n}+\rho_{\beta} \beta_{m n}+\rho_{\gamma} \gamma_{m n}\right)
\end{aligned}
$$

Constraints:

$$
\begin{array}{ll}
\sum_{m=1}^{i} h_{m n}=1 & \forall n \\
\sum_{n=1}^{j} h_{m n} \leq 1 & \forall m \\
h_{m n}=0,1 & \forall m, n
\end{array}
$$

Formula (10) refers every post must arrange one staff to operate; Formula (11) refers each staff can only work on a post; Formula (12) refers the value of $h_{m n}$ can only be 0 or 1. Formula $h_{m n}=0$ refers don't arrange $p_{m}$ to $s_{n}$, formula $h_{m n}=1$ refers arrange $p_{m}$ to $s_{n}$.

\section{HEURISTIC ALGORITHM SOLUTION}

According to the fishing work's specialty of the pelagic fishery, during the catch processing, fresh degree and integrity of the catch will affect their quality and sale, especially the commodity catch's quality. When the catch is on board by purse seining and trawling, first thing is priority divid ing. The catch with high economy degree will have priority arrangement for processing, then the others.

The paper designs a kind of heuristic algorith $m$ with the goal of maximizing the post competency degree based on Hungarian algorithm to solve the personnel allocation, and gives priority to the high priority catch's person configuration.

\section{A. Build competency level matrix}

According to above, the personnel competency level matrix $\mathrm{W}$ can be expressed as: 


$$
\mathrm{W}=\left[\begin{array}{cccc}
w_{11} & w_{12} & \cdots & w_{1 n} \\
w_{21} & w_{22} & \cdots & w_{2 n} \\
\vdots & \vdots & \ddots & \vdots \\
w_{m 1} & w_{m 2} & \cdots & w_{m n}
\end{array}\right]
$$

Assume that it has $b$ kinds of the catch, $Q_{a}$ represents the waiting process catch named with $a$, $a \in\{1,2, \ldots, b$, then choose the high economy catch to get the person configuration for their processing and form a matrix.

\section{B. Solution process of heuristic algorithm}

Step1: Choose the high economy between the waiting processing catch to get the person configuration, and then choose the corresponding processing post to form the matrix $\mathrm{W}^{*}$. In the matrix $\mathrm{W}^{*}$, search each column element from left to right, if ${ }^{S^{*}}$ post's corresponding $n^{*}$ column elements only have one nonzero, then give ${ }^{s^{*}}$ post allocation to the $p_{m^{*}}$ person of the row where this element on and delete the row and column where this element on. Repeating the above process until every column has more than one non-zero element and refresh the matrix.

Step 2: For the person configuration of the less person post, getting the statistic of all posts corresponding column non-zero elements and sorting the matrix's columns from left to right according to the number of their non-zero elements from few to more, and then get the refreshed matrix. The columns with few number of non-zero elements can get the priority configuration to get rid of no solution.

Step3: In the refreshed matrix, search the row and column elements from left to right and mark the maximum element of every row and every column.

After the marking, if $S_{n}{ }^{*}$ post's corresponding $n^{*}$ column element had been marked twice, then put the $p_{m}{ }^{*}$ person corresponded with the row where this element in on ${ }^{s^{*}}$ post and delete the row and column where it be, then refresh the matrix.

Step 4: Search the matrix, if the row or column has single non-zero element, then go back to step1 to step3 until the matrix has no twice marked or single non-zero element.

Step 5: Put the $p_{m^{*}}$ person who corresponding with the maximum element in the first column into the $S_{n}$ * post and go back to repeat the step1 to step 4 until the matrix $\mathrm{W}^{*}$ is empty, then researchers have the configuration matrix $\mathrm{C}^{*}$.

Step 6: Repeat step1 to step5 until all catch $Q_{a}$ has its configuration.

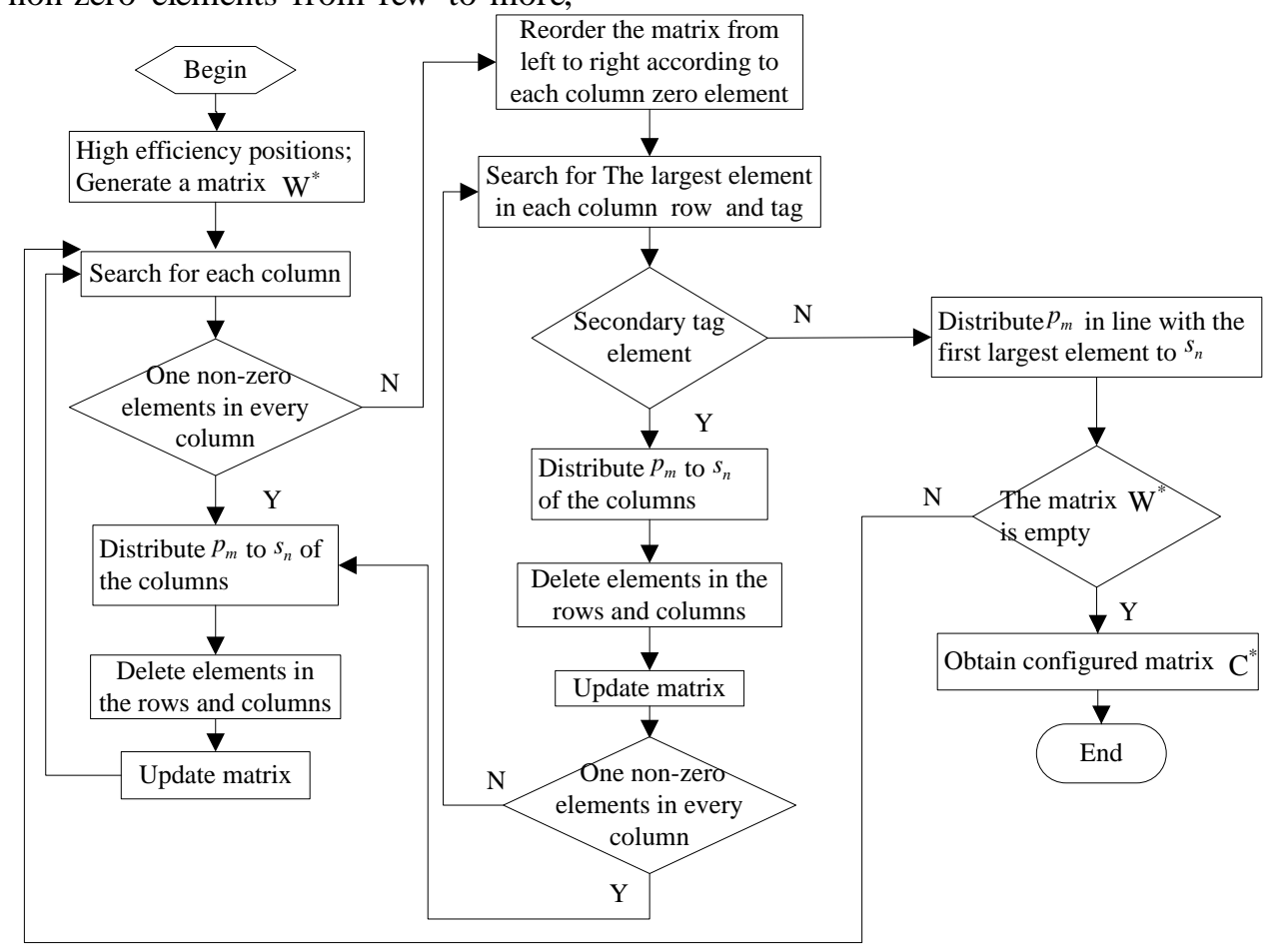

Figure 1. Heuristic algorithm process. 


\section{PElAGiC FISHING Work SyStem AND EXAMPLES ANALYSIS}

\section{A. Pelagic fishing work system}

Pelagic fishing work system includes the process on board and workers. The process has three parts: putting net down, drawing the net back and processing the catch. Fishing influences the quantity of the catch, drawing the fish back and catch processing are the important parts to keep the quality of aquatic product.

Take the single net technology of the stern ramp trawler as the example, after drawing the net back and getting the fish, it will have some other fishes except the catch with economy in the net, so researchers should divide the different fish in the process. Its concrete operation process is shown as below:

On the pelagic fishing ship, most mariners are participating in the process. Because the pelagic fishing ships are far away from the coast, it is difficult to plus or minus persons, so the number of people on the ship is changeless and the number is not big, according to the size of the ship, the number is between a few to dozens. The people on the ship should be arranged to the posts include the Fig. 1 and researchers should ensure that any post has at least one person to operate. The efficiency of the operation also relates to the quantity and quality of the catch.

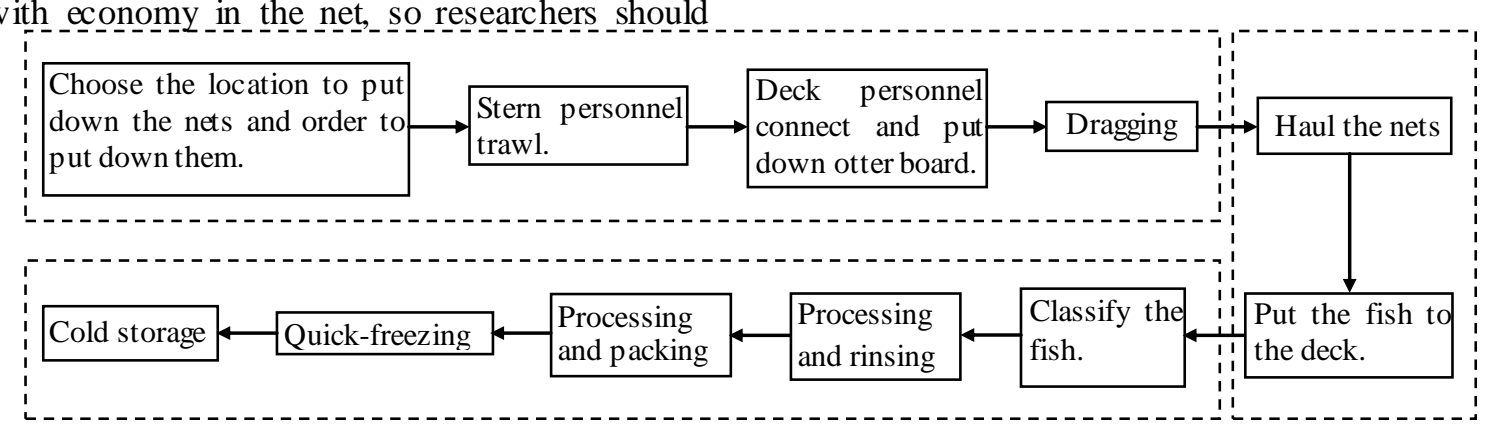

Figure 2. The fishing process of tern ramp fishing net

\section{B. Examples analysis}

Fig. 2 shows the process of the single net technology of the stern ramp trawler, the whole process includes 11 parts. For calculating the model easily, the paper has two assumption as follows:(1)Generally, choosing the location to put the net down and pulling and drawing it back are completed by the machines with people's operation. Assume that the people on these process are been neglected;(2)It needs two or more persons to complete the connection of net plank and put it down, these posts can be denoted as $s_{n}^{1}, s_{n}^{2}, \ldots$, and they have the same attributes and priorities. In order to simplify the calculation of the examples, this paper assumes that each post has one person and there are 10 people on the ship.

This fish process line has 8 posts, denoted them as $s_{1}, s_{2}, s_{3}, \ldots, s_{8}$ one by one; the waiting process catch include Gadus and other fish, denoted as $\mathrm{Q}_{1}$ and $\mathrm{Q}_{2}, \mathrm{Q}_{1}$ has the higher priority than $\mathrm{Q}_{2}$.Among $\mathrm{Q}_{1}$, all the posts are for fish processing and the $\mathrm{Q}_{2}$ posts for processing are $s_{1}, s_{2}, s_{3}, s_{4}, s_{5}, s_{7}, s_{8}$.
Analyzing the $\mathrm{Q}_{1}$ example and choosing the each person's work data in 20 days, then researchers can get the personnelcompetency level matrix $\mathrm{W}^{*}$ is:

$$
\left[\begin{array}{cccccccc}
0 & 0.689 & 0.348 & 0 & 0.882 & 0 & 0 & 0 \\
0 & 0.476 & 0.572 & 0 & 0.435 & 0.288 & 0.543 & 0 \\
0 & 0 & 0.928 & 0 & 0 & 0.217 & 0 & 0.556 \\
0.645 & 0 & 0.225 & 0.451 & 0.364 & 0 & 0.598 & 0 \\
0 & 0 & 0 & 0.387 & 0.765 & 0.268 & 0.652 & 0.456 \\
0.334 & 0.460 & 0 & 0.789 & 0 & 0.893 & 0 & 0.367 \\
0 & 0.475 & 0 & 0.364 & 0.266 & 0 & 0 & 0.467 \\
0.472 & 0.674 & 0 & 0.872 & 0.475 & 0 & 0.869 & 0 \\
0 & 0.463 & 0 & 0 & 0.785 & 0.653 & 0.253 & 0.266 \\
0.561 & 0 & 0.455 & 0.675 & 0 & 0.641 & 0 & 0.732
\end{array}\right]
$$

According to the above heuristic algorithm, the problem can be solved and the final configuration results get as follows: 


$$
C^{*}=\left[\begin{array}{llllllll}
0 & 0 & 0 & 0 & 1 & 0 & 0 & 0 \\
0 & 1 & 0 & 0 & 0 & 0 & 0 & 0 \\
0 & 0 & 1 & 0 & 0 & 0 & 0 & 0 \\
1 & 0 & 0 & 0 & 0 & 0 & 0 & 0 \\
0 & 0 & 0 & 1 & 0 & 0 & 0 & 0 \\
0 & 0 & 0 & 0 & 0 & 1 & 0 & 0 \\
0 & 0 & 0 & 0 & 0 & 0 & 0 & 0 \\
0 & 0 & 0 & 0 & 0 & 0 & 1 & 0 \\
0 & 0 & 0 & 0 & 0 & 0 & 0 & 0 \\
0 & 0 & 0 & 0 & 0 & 0 & 0 & 1
\end{array}\right]
$$

Finally, researchers can calculate that the personnel competency level sum of the $\mathrm{Q}_{1}$ fish process line is 5.812, the detailed people and post plan is showed by Tab.1:

TABLE I. The Result OF FISHING OPERATION PeOPle DISTRIBUTION

\begin{tabular}{|c|c|c|}
\hline Post No. & Post & Person No. \\
\hline$s_{1}$ & People trawl & $p_{4}$ \\
\hline$s_{2}$ & $\begin{array}{c}\text { Connect and put } \\
\text { screen }\end{array}$ & $p_{2}$ \\
\hline$s_{3}$ & Putting fish to deck & $p_{3}$ \\
\hline$s_{4}$ & $\begin{array}{c}\text { Classification } \\
s_{5}\end{array}$ & $\begin{array}{c}\text { Processing and } \\
\text { flushing }\end{array}$ \\
\hline$s_{6}$ & $\begin{array}{c}\text { Processing and } \\
\text { packing }\end{array}$ & $p_{1}$ \\
\hline$s_{7}$ & $\begin{array}{c}\text { Frozen } \\
\text { Quite-frozen }\end{array}$ & $p_{8}$ \\
\hline$s_{8}$ & p \\
\hline
\end{tabular}

\section{CONCLUSIONS}

SHANGHAI SCIENCE AND TECHNOLOGY INNOVATION ACTION PLAN (12231203902) : KEY TECHNOLOGY RESEARCH AND APPLICATION OF IOT INTELLIGENCE SERVICE OF PELAGIC FISHING BOATS AND OPERATING SYSTEM.

In the pelagic fish processing, optimizing the people configuration on the ship can increase the efficiency of the production operation to realize the mariners' self value, but also can help to get rid of the unreasonable configuration and post miss and people redundancy et al. Caused by personnel wrong judgments. On account of the specificity of the pelagic fishing, the paper confirms the reasonable element for personnel competency through the analysis of the fish operation process on ship and builds personnel competency level matrix based on it. Aimed at the optimization goal that maximizing the competency, this paper builds the personnel competency optimization model and designs one heuristic algorithm to solve the model, then makes the people optimization configuration on ship come true.

\section{REFERENCES}

[1] L. CAO, B. WANG, and F. LIU, 3rd ed. "Mixed-skill worker assignment optimization model for assembly line," Journal of Chongqing university, vol.33, pp. 21-26, 2010.

[2] W. L. SHEN, L. HUANG. "Allocation optimization of assembly line workers based on combination-Weighting," Journal of Hefei University of Technology, vol. 36, pp. 1034-1037,2013.

[3] Z. LIU, J. J. TANG, and R. J. XIE, 3rd ed. "Evaluationindex and method research of employees postcompetence on the production line," Journal of Anhui Engineering University, vol. 29, pp. 23-26, 2014.

[4] D. DU, Q. H. PANG. "Modern comprehensive evaluation method and case selection," Beijing, Tsinghai University Press, 2015, pp.138-145.

[5] G. CELANO, A. COST A, and S. FICHERA, 3rd ed. "Human factor policy testing in the sequencing of manual mixed model assembly lines," Computers \& Operations Research , vol31, pp.3959,2004

[6] T. Majozi, X. X. Zhu. "Impact of personnel allocation on deterministic planning and scheduling," AIChE Journal, vol. 50, pp. 999-1016, 2014.

[7] P. ZHENG, J. Q. LI. "Evaluation method of supply chains performance based on BP neural net works," Operations Research and Management, vol. 19,pp. 26-31, 2010.

[8] A. T. ERNST. Staff scheduling and roistering: a review of applications, methods and models [J] European Journal of Operational Research, vol. 153, pp. 3-27, 2004.

[9] Y. DING, C. Y. LIANG, and J. H. ZHU. "A research on knowledge management performance evaluation method in the supply chains," Operations Research and Management, vol. 15, pp.148-154, 2006.

[10] C. Q. WANG, Z. Y. NHANG, and W. L. XU. "Research of Determining Index Weights Based on Least SquaresMethod in Post-Evaluation Process," Journal of Jilin University, vol. 28, pp. 513-518,2010.

[11] H. L. DING, F. WANG. "Finite element analysis of the structural strength for a guided bomb," Sciencetechnology and engineering, vol. 9, pp. 76-79, 2009. 